\title{
Knowledge, attitude and prescription practice of menopausal hormone replacement therapy by doctors in UITH, Ilorin Nigeria.
}

\author{
"Olarinoye J.K.. , Olarinoye A.O. ${ }^{2}$, Saka M.J. ${ }^{3}$, Ajiboye P.O. ${ }^{4}$, Olagbaye B.A. ${ }^{5}$, Okoro P.O. ${ }^{1}$ and \\ Sanya E.O. ${ }^{1}$
}

\begin{abstract}
Objective: This study aimed to evaluate the knowledge, attitude and prescription practice of menopausalHRT (mHRT) by doctors in UITH, Ilorin.

Method: All consenting doctors in O\&G, Internal Medicine, Family Medicine, Public Health and Interns at the UITH completed a structured questionnaire. SPSS software version 22 was used for analysis. Associations between categorical variables were tested using the chi-square $(\chi 2)$ while the student-t test was used for the continuous variables $(\mathrm{p}<0.05)$.

Results: Eighty doctors, 56 males and 24 females responded. Majority (63.8\%) rated their knowledge of mHRT average; (17.5\%) believed they had good knowledge, while (18.7\%) had poor knowledge. Gynaecologists had the highest mHRT Knowledge Score (72.4) while public health doctors had the lowest (33.7), (83.7\%) had no formal training on the use of mHRT. Fifty-five percent did not think menopause should be treated. Just $25 \%$ prescribed mHRT where $58.8 \%$ had no reason for not prescribing. Only $18.8 \%$ had ever referred menopause patients to specialists. Forty percent use alternative therapies for menopausal symptoms, majorly vitamins and herbs.
\end{abstract}

Conclusion: The knowledge, attitude and prescription practice of the studied doctors was poor. Trainings are still needed in this area.

Keywords: Menopause; hormone replacement therapy; doctors

\author{
*Corresponding author \\ Olarinoye J.K. \\ http://orcid.org/0000-0002-0731-4593 \\ Email:kolaolarinoye@yahoo.com
}

${ }^{1}$ Department of Medicine, University of Ilorin, Ilorin, Nigeria

${ }^{2}$ Department of Obstetrics and Gynaecology, University of Ilorin, Nigeria.

${ }^{3}$ Department of Community Health, University of Ilorin, Nigeria

${ }^{4}$ Department of Behavioural Sciences, University of Ilorin, Nigeria.

${ }^{5}$ Department of Anatomy, University of Ilorin, Ilorin, Nigeria 


\title{
Connaissance, attitude et prescription pratique de la thérapie de remplacement de l'hormone menopausal par des médecins d'UITH, Ilorin, Nigéria
}

\author{
"Olarinoye J.K. ${ }^{1}$, Olarinoye A.O. ${ }^{2}$, Saka M.J. ${ }^{3}$, Ajiboye P.O. ${ }^{4}$, Olagbaye B.A. ${ }^{5}$, Okoro P.O. ${ }^{1}$ and \\ Sanya E.O. ${ }^{1}$
}

\section{Résumé}

Cette étude visait à évaluer les connaissances, l'attitude et la pratique en matière de prescription de HRT ménopausique (mHRT) par des médecins d'UITH, Ilorin.

Méthode de l'étude: Tous les docteurs en $\mathrm{O} \& \mathrm{G}$, en médecine interne, en médecine familiale, en santé publique et en santé publique et les stagiaires de l'UITH ont rempli un questionnaire structuré. La version 22 du logiciel SPSS a été utilisée pour l'analyse. Les associations entre les variables catégorielles ont été testées à l'aide du chi-carré (2), tandis que le teste d'étudiant était employé pour les variables continues (p $<0.05)$.

Résultat : Quatre-vingt (80) médecins, 56 hommes et 24 femmes ont répondu. La majorité (63.8\%) ont évalué leur connaissance de la moyenne de mHRT; (17.5\%) pensaient avoir de bonnes connaissances, alors que (18.7\%) avaient de faibles connaissances. Les gynécologues avaient le score de connaissances mHRT le plus élevé (72.4), tandis que les médecins de la santé publique avaient le score le plus bas (33.7), $(83.7 \%)$ n'avait aucune formation officielle sur l'utilisation des mHRT. Cinquante-cinq pour cent ne pensaient pas que la ménopause devrait être traitée. Seulement $25 \%$ ont prescrit un mHRT alors que $58.8 \%$ n'avaient aucune raison de ne pas le prescrire. Seulement $18.8 \%$ avaient déjà référé des patientes ménopausées à des spécialistes. Quarante pour cent ont recours à des thérapies alternatives pour traiter les symptômes de la ménopause, principalement les vitamines et les herbes.

Conclusion: Les connaissances, l'attitude et la pratique en matière de prescription des médecins étudiés étaient médiocres. Des formations sont encore nécessaires dans ce domaine.

Mot-clé : Ménopause, traitement hormonal substitutif, médecins

\author{
*Auteur correspondant \\ Olarinoye J.K. \\ http://orcid.org/0000-0002-0731-4593 \\ Email:kolaolarinoye@yahoo.com \\ ${ }^{1}$ Department of Medicine, University of Ilorin, Ilorin, Nigeria \\ ${ }^{2}$ Department of Obstetrics and Gynaecology, University of Ilorin, Nigeria. \\ ${ }^{3}$ Department of Community Health, University of Ilorin, Nigeria \\ ${ }^{4}$ Department of Behavioural Sciences, University of Ilorin, Nigeria. \\ ${ }^{5}$ Department of Anatomy, University of Ilorin, Ilorin, Nigeria
}

Research Journal of Health Sciences subscribed to terms and conditions of Open Access publication. Articles are distributed under the terms of Creative Commons Licence (CC BY-NC-ND 4.0). (http://creativecommons.org/licences/by-nc-nd/4.0).

http://dx.doi.org/10.4314/rejhs.v7i4.6 


\section{INTRODUCTION}

Menopause is a physiological event that signifies the end of a woman's 33 reproductive life due to permanent loss of ovarian follicular function (1). The hormonal changes at menopause are associated with numerous physical, emotional and sexual dysfunctions of varying severity. Among the commonly encountered symptoms of menopause are hot flushes, vaginal dryness with dyspareunia, urogenital symptoms, mood changes, sleep disorders as well as osteoporosis and heightened risk of cardiovascular disease $(1,2)$.

Over the years, Hormone Replacement Therapy (HRT) has been used successfully to treat menopause-related vasomotor symptoms and to protect against osteoporosis (2). However, a number of side-effects have also been observed with its use. Women's Health Initiative (WHI), a multi-centre randomised controlled trial of Oestrogen plus Progestin among 16,608 American post-menopausal women with intact uteruses showed a significant increase in hazard risk for invasive breast cancer, stroke, coronary artery disease and venous thrombosis (3). On the other hand, according to the study, menopausal HRT (mHRT) seemed to be protective against osteoporosis, colorectal cancer and endometrial carcinoma (3).

Some researchers however tried to do a re-analysis of the WHI data and found that the side effects may not be as serious as earlier portrayed $(4,5)$. In spite of this, many physicians and patients still have reasons to question the safety of menopausal hormone therapy (6). There is also no consensus among the various practice regulatory bodies with regards to use of HRT in menopause.

In an Enugu based study in 2009, less than $1 \%$ of the 209 women studied were aware of mHRT and none had ever been treated with it (7). A similar study carried out in Benin showed that none of the women studied was on mHRT and only $7.3 \%$ had awareness about it (8). This is partly because of unwillingness on the part of the women to use them and also because of prescription inertia on the part of the physicians. A recommendation by a doctor is a major determinant of mHRT use among the women. Majority of non-users would consider mHRT if so recommended by their doctor $(2,9)$.

It is important therefore that doctors attending to menopausal women familiarise themselves with the current guidelines in the use of mHRT and form a practice opinion that is evidence-based and that will give optimal quality of mid-life health to their clients. This study therefore set out to evaluate the doctors' knowledge, attitude and prescription practice of HRT for menopause-related symptoms.

\section{General Objective}

To determine the knowledge, attitude and current prescription practice of menopause-HRT (mHRT) by doctors in University of Ilorin Teaching Hospital (UITH), Ilorin, Nigeria.

\section{Specific objectives}

1. To determine the knowledge base of the doctors concerning the indications, contra-indications, effects and side effects of mHRT use in menopause

2. To assess their views and attitudes about use of mHRT to treat menopausal symptoms

3. To determine their current prescription practice.

\section{MATERIALS AND METHODS}

Study Site: The study took place at University of Ilorin Teaching Hospital (UITH), Ilorin, Nigeria. Ilorin is the capital city of Kwara state located in the Middle Belt of the country with a population of 781,934 according to 2006 national population census (10). The hospital is a 500-bed third-tier healthcare facility that serves as a referral centre for the whole state and its environs. It has virtually all the major clinical departments and units like Internal medicine, Surgery, Obstetrics and Gynaecology, Paediatrics, Family Medicine, Geriatrics as well as Community Medicine and Public Health.

Study Design: It was a descriptive crosssectional study.

Study Population: All medical practitioners in UITH attending to women in menopausal age group

Sample Size Determination: All consenting doctors that met the inclusion criteria

\section{Inclusion Criteria}

1. All doctors in Obstetrics and Gynaecology Department

2. Doctors in Internal Medicine

3. Family Physicians

4. Public Health Physicians

5. Interns

\section{Exclusion Criteria}

1. Any doctor that was not in active practice 
during the study period

2. Any doctor not regularly attending to women in menopause or peri-menopause (less than 5 per month)

\section{Method}

Each study candidate was interviewed via a selfadministered questionnaire with several domains including:

1. Socio-demographics

2. Knowledge of mHRT

3. Views and attitudes towards mHRT

4. Prescription practice of mHRT

\section{Research Instrument}

The research tool was a self-administered questionnaire developed from some other questionnaires that have been used in previously published works on the same topic $(11,12,13)$. The questionnaire is a 57-item questionnaire under 3 domains:

i. Knowledge domain has 29 questions on indications and contra-indications to the use of mHRT

ii. Attitude domain has 16 questions while

iii. Practice domain has 12 questions

Scoring of Domains: Domain scores are based on the current practice guidelines on menopausal HRT $^{1}$. A mark was awarded for a correct answer while a wrong answer or un-attempted question attracted no mark.

Knowledge Score: The global Knowledge Score was computed by transforming the sum total score for Knowledge Domain on a scale of 0 to 100 , where 0 represents "No knowledge at all" and 100 represents "highest knowledge attainable".

Sampling Technique: The doctors that met the inclusion criteria were identified and contacted. Detailed information about the study was given to all the prospective candidates and questionnaires were served following verbal consent.

Statistical Analysis: Data were analysed using the SPSS statistical software version 22 (14). Continuous variables were generated as means \pm s.d while the categorical variables were presented as frequency and proportions. Associations between categorical variables were tested using the chi-square $\left(\chi^{2}\right)$ while the student- $t$ test was used for the continuous variables. A $p$ value of $<0.05$ was taken as statistically significant difference.
Ethical Consideration: Ethical approval for the study was gotten from the Ethics and Research Committee of the University of Ilorin.

Benefit to Science: Doctors are known to play crucial role in providing medical education for patients in Africa. The results from this study will help in formulating a policy about training and retraining of healthcare specialists in Nigeria with regards to management of menopause-related complaints.

Benefit to Individuals: Up-to-date knowledge and evidence-based practice among the doctors will assist them to take health decisions that will improve the overall quality of life for climacteric Nigerian women.

Funding: The study was fully funded by the researchers. It was carried out at no cost to the respondents.

\section{RESULTS \\ Demographic Findings}

Eighty doctors were recruited from the University of Ilorin Teaching Hospital in Kwara State. $70 \%$ (56) male and 30\% (24) female. Majority $67(83.75 \%)$ were of the Yoruba tribe while the remaining $13(16.25 \%)$ were from other ethnic groups. Twenty-four (30\%) were from the department of internal medicine, $13(16.2 \%)$ were from Family Medicine, 19 (23.8\%) were from Obstetrics and Gynaecology, 15(18.8\%) were Public Health physicians while the remaining $9(11.2 \%)$ were Interns. A total of 46 (57.5\%) were Christians while 33 (41.3\%) were Muslims while one of the respondents did not subscribe to any religion.

\section{Doctor's Knowledge of mHRT}

From the self-assessment of mHRT knowledge, a huge majority $51(63.8 \%)$, rated their knowledge average; only $14(17.5 \%)$ believed they had good knowledge of HRT, while $15(18.7 \%)$ admitted that their knowledge of menopausal-HRT was poor. Only $13(16.3 \%)$ claimed to have had any formal training on the use of menopausal hormone replacement therapy in the last 5years, the other $67(83.7 \%)$ agreed they had no formal training.

As many as $20(25 \%)$ of the doctors did not have any source of information about $\mathrm{mHRT}$; $32(40 \%)$ referred to textbooks, $17(21.3 \%)$ consulted journals, $7(8.8 \%)$ said they got information from lectures, $3(3.8 \%)$ claimed to have accessed mHRT information through the 
internet while one of the respondents had multiple sources of information.

On the use of mHRT, $28(35 \%)$ of the respondents submitted that they had no idea of how long HRT should be administered. Twentyone $(26.25 \%)$ felt it should not be taken for more than 5 years, an equal proportion of respondents also felt mHRT could be used for up to 10years, $2(2.5 \%)$ said it could be used for more than 10years while $8(10 \%)$ believed it could be used indefinitely.

\section{Doctor's mHRT Knowledge Score}

Mean mHRT knowledge score was 53.3 $( \pm 2.8)$ as shown in Table 4 . The study shows that male doctors have significantly higher knowledge scores (57.4) than their females counterparts $(44)(p=0.03)$. The gynaecologists had the highest mHRT knowledge score (72.4) while the public health physicians had the lowest rating of $33.7(\mathrm{p}=0.00)$.

A linear association was observed in the mHRT knowledge score and Awareness. Those who claimed to have good awareness of mHRT had a significantly higher score (71.2) than those with poor awareness (45) $(\mathrm{p}=0.03)$, while those who had formal training also had a significantly higher score (73.1) than those without any formal training $(\mathrm{p}=0.007)$.

There was no significant association between knowledge of HRT and year of graduation $(p=0.25)$ nor with age group $(p=0.155)$. In addition, no observable difference in the doctors' knowledge of HRT between the two main religious groups in Nigeria. $(p=0.641)$.

\section{Doctor's Recommendation of mHRT for Treatment of Menopausal Symptoms}

From the study, 21 (26.3\%) believed menopause is a physiological condition, $57(71.2 \%)$ believed that menopause symptoms are clinical conditions, while $2(2.5 \%)$ of the doctors agreed they don't know.

Out of the 80 doctors, 33(41.2\%) thought menopausal symptoms should be treated, 44 $(55 \%)$ believed it should not be treated clinically while $3(3.8 \%)$ said they don't actually know.

\section{Doctor's Opinion on Contraindications to use of mHRT (Table 3)}

Sixty-five $(81.3 \%)$ doctors were of the opinion that mHRT was contraindicated in women with breast cancer and $56 \%$ of them would not recommend it for patients with family history of breast cancer. About equal number 58 $(72.5 \%)$ opined that mHRT should not be used in
Endometrial Carcinoma and Deep Vein Thrombosis while up to $(65 \%)$ of them felt same way for women with stroke. mHRT was deemed contraindicated in hypertension by $36(45 \%)$ and $26(32.5 \%)$ for women with diabetes mellitus.

\section{Doctor's Practice of mHRT}

Out of the 80 doctors that responded, a total $76(95 \%)$ indicated that they attended to menopause women while the remaining 4(5\%) did not. Twenty (25\%) saw more than 10 menopausal women every month, $24(30 \%)$ saw between 5 and 10, while $32(40 \%)$ did not see beyond 5 menopause women in a month.

Although as many as $59(73.8 \%)$ out of the 80 respondents indicated that they encountered menopause-related symptoms on a regular basis, only $29(36.3 \%)$ of the 80 doctors discussed menopause with their patients.

It is worthy of note that, only a quarter, 20 $(25 \%)$ of the 80 respondents prescribed HRT in any form for menopause related symptoms, $60(75 \%)$ did not prescribe at all.

Twelve (15\%) did not prescribe mHRT for fear of side effects, $47(58.8 \%)$ had no reason for not prescribing while the remaining one person did not believe in $\mathrm{mHRT}$ at all.

Twelve (15\%) prescribed oral form of mHRT, $6(7.5 \%)$ prescribed vaginal cream while $2(2.5 \%)$ prescribed injectable. Whereas, out of the 20 doctors that prescribed mHRT, only five $(25 \%)$ indicated that they encountered side effects, $15(75 \%)$ admitted mHRT was quite effective.

With regards to patient referral, only $15(18.8 \%)$ out of the 80 respondents had ever referred patients to a specialist because of menopause issues, $11(73.3 \%)$ out of these 15 doctors referred to the gynaecologists, $2(13.3 \%)$ of them referred to physicians while the remaining 2(13.3\%) did not indicate the specialty they refer to.

$32(40 \%)$ of the 80 doctors indicated that they used alternative methods to treat menopause symptoms. 19(23.75\%) prescribed vitamins, 10 $(12.5 \%)$ encouraged the use of herbal mixtures while the remaining $3(3.75 \%)$ did not indicate what they prescribed as alternative method.

\section{DISCUSSION}

This is the first time the knowledge base of health care providers about use of menopausal hormone replacement therapy is being evaluated in Nigeria. Majority of the studied doctors lacked self-confidence when handling issues about mHRT. This study shows that only a very small 
proportion of the physicians in UITH Ilorin $(17.5 \%)$ demonstrated self-confidence in the practice of mHRT, while a vast majority $(63.8 \%)$ admitted that their knowledge about use of mHRT in treating menopausal symptoms was only average.

In Africa, most women in the postmenopausal age group are illiterate and therefore depend heavily on their doctors and other health care providers for health-related information $(7,8)$. Where the knowledge base and selfconfidence of the health care provider (HCP) is lacking or deficient, it will impact negatively on the patients' overall health-related quality of life $(7,8)$.

In spite of a plethora of information about menopausal hormone therapy available in the public domain like journals, review articles and practice guidelines $(7,8,15,16,17,18,19)$. It is surprising to note in this study that as many as $25 \%$ of the studied physicians claimed that they did not have any source of information at all about mHRT. Only $16.3 \%$ had at least one update training related to menopause care in the past 5 years. These figures are comparable to the findings in a similar study (15) in the Middle East where $82.4 \%$ of primary health care physicians surveyed had just moderate knowledge of mMHRT (15). In that same study, the majority of the respondents were oblivious of the benefits of mHRT described in literatures.

Using the menopause - HRT Knowledge Score, the mean mHRT score was 53.3. This clearly showed that the mHRT-knowledge base of doctors attending to menopausal women in Ilorin, Nigeria was grossly deficient compared to results from other developed countries $(13,16,17)$. A similar study carried out in Ontario, Canada showed that the physicians' knowledge about mHRT was consistent with recommendations in the published literature (13).

Our study also found out that the gender of the doctor, the speciality of practice, access to formal training and re-training as well as selfperception were the factors that were significantly associated with mHRT knowledge. Male doctors appeared to be more knowledgeable. This is paradoxical in the sense that women would naturally be expected to take more interest in women health. Those who had formal training in menopause as well as those in Obstetrics and Gynaecology appeared to fare better than others. Religion, tribe and graduation year of the doctors did not appear to play any significant role.

In our study, most of the physicians interviewed $(88.8 \%)$ were aware of the positive benefits of mHRT in relieving vasomotor symptoms like hot flushes, vaginal dryness and dyspareunia only a very few believed in its usefulness in cardio-protection and stroke prevention. Other symptoms that seem to enjoy the attention of doctors in menopause include loss of libido and osteoporosis. Earlier studies looking at the benefits of menopause - HRT showed that mHRT had a complex pattern of risk and benefits 16,23). While it was considered appropriate for symptom management in some women, its use for chronic disease prevention had to be done with caution (16). A more recent reanalysis of the same old data however opined that the side effects attributable to MHRT might not be as deleterious as earlier claimed (17).

Almost all the doctors interviewed attend to women in post-menopausal age group and encounter menopausal symptoms quite reasonably well. But it is surprising that only $36.3 \%$ discuss menopause with their patients and only $25 \%$ have ever prescribed MHRT in any form at any time. Most doctors do not have any reason for not prescribing while some hesitate to prescribe because of fear of side effects. In the earlier referenced Middle-East study (15), 88\% of the Primary Health Care physician studied discussed menopausal symptoms with their clients while $45.1 \%$ recommended mHRT for them. This shows that the prescription rate for mHRT among Nigerian doctors is quite low compared to other parts of the world. This figure is however a slight improvement over the findings in some earlier Nigerian studies where prescription was absolutely nil $(7,8)$.

Nigerian doctors need to update their knowledge of HRT to treat menopausal symptoms, such that those who would benefit from hormonal intervention will not be denied and the others would not be unduly exposed to the side effects. This will enhance the overall healthrelated quality of life of the women in this age group. It is particularly imperative because, with global improvement in health standard, more women will spend longer period of their lives in menopausal years, and their doctors need to have enough knowledge base to provide optimal, evidence-based health care $(1,3)$.

Majority $(75 \%)$ of prescribers in our study found mHRT to be effective and a very small proportion of them $(25 \%)$ encountered at least one side effect during its use. This finding is consistent with existing literatures and practice guidelines where menopause HRT is judged to be effective for control of menopausal symptoms 
with minimal side effects if patients are well selected. It is now self-evident that doctors in Nigeria need to update their knowledge of mHRT to beat their prescription inertia.

With respect to the use of alternative treatment options for managing menopausal symptoms, close to half $(40 \%)$ of the subjects used one form of alternatives or the other. The most commonly used alternatives were vitamins and herbs. A similar cross-sectional study showed that most Nigerian gynaecologists preferred to treat severe menopausal symptoms with psychotherapy and anxiolytics (21). Several other therapeutic alternatives abound globally for combating climacteric symptoms but they have not been well studied in Africa $(8,21)$. It would be desirable to subject these products to thorough scientific scrutiny before committing them to clinical use.

\section{CONCLUSION}

The knowledge base of doctors in Ilorin, Nigeria about menopause-HRT was far less than their counterparts in developed countries. Training and continuous re-training in use of mHRT should be encouraged in all medical schools and residency training programmes in Nigeria. This will foster evidence-based practice among the physicians and thus promote menopausal health-related quality of life.

Conflicts of interest: The authors declares no conflicts of interest.

\section{REFERENCES}

1. The North American Menopause Society. Menopause - Clinical Care Recommendations (Internet). 2015 (Cited 2015 Oct 20).

Available from:

http://www.menopause.org/publications/clinica 1 - care-recommendations/chapter-1 menopauseEstrogen

2. Hamid S, Al-Ghufli F R, Raessi H A, Al Dhufairi K M, Al-Dhaheri N S, Al-Maskari F et al. Women's knowledge, attitude and practice towards menopause and hormone replacement therapy: a facility-based study in Al-ain, United Arab Emirates. J Ayub Med Coll Abbottabad 2014;26(4):448-54.

3. Writing group for the Women's Health Initiative Investigators. Risks and benefits of Estrogen and Progestin in healthy postmenopausal women. Principal results from the Women's Health Initiative randomized controlled trial. JAMA 2002;288,3:321-33.

4. Rossouw JE, Prentice RL, Manson JE, Wu L, Barad D, Barnabei VM et al. Postmenopausal hormone therapy and the risk of cardiovascular disease by age and years since menopause. JAMA. 2007;297(13):1465-77.

5. Hill DA, Hill SR. Counselling patients about hormone therapy and alternatives for menopausal symptoms. Am Fam Physician.2010;82(7):801-7.

6. Shafi S, Samad Z, Syed S, Sharif A, Khan MAU, Nehal US et al. Hormone replacement therapy menopause with a better future - a survey of views on hormone replacement therapy (HRT). JPMA 2001;51:450-5.

7. Nkwo P. Treatment Preferences And Awareness Of HRT Among Nigerian Menopausal Women. The internat $\mathrm{J}$ of Geriatrics and Gerontology 2009; 6(1): 1. 2009;5.

8. Ande AB, Omu OP, Ande OO, Olagbuji NB. Features and perceptions of menopausal women in Benin City, Nigeria. Annals of African Medicine 2011;10(4):300-4.

9. Roberts PJ, Sibbald B. Hormone replacement therapy: the views of general practitioners and practice nurses. British Journal of General Practice 2000;50:986-91.

10. National Population Commission, Nigeria. POPULATION DISTRIBUTION BY SEX, STATE, LGAS AND SENATORIAL DISTRICT: 2006 CENSUS PRIORITY TABLES, VOL 3 (Internet) 2006. (Cited 2015 Nov 1).

A v a i 1 a b 1 e a t : http://www.population.gov.ng/index.php/public ations/140-population-distribution-by-sexstate-lgas-and-senatorial-district-2006-censuspriority-tables-vol-3.

11. Mueller KA, Sanchez GJ, Sievert LL. Sources of information and HRT prescribing practices among gynecologists in Puebla, Mexico. Maturitas. 2003 Jun 30;45(2):137-44.

12. Pereira Filho AS, Júnior JM, Arkader J, Maciel GA, Baracat EC. Attitudes and practices about postmenopausal hormone therapy among female gynecologists in Brazil. Maturitas. 2005 Jun 16;51(2):146-53..

13. Elinson L, Cohen MM, Elmslie T. Hormone replacement therapy: a survey of Ontario physicians' prescribing practices. Cmaj. 1999 Sep 21;161(6):695-8.

14. IBM SPSS Statistics for Windows, Version 22.0. Armonk, NY: IBM Corp

15. Al-Eassa AA, Al-Fadel AM, Al-Ajmi MA, AlNajjar AA, Makboul GM, Elshazly M. Knowledge and attitude of primary care doctors towards management of postmenopausal symptoms. Alexandria Journal of Medicine. 2012;48(2).

16. Manson, J.E., Chlebowski, D.R.T., Stefanick, M.L., Aragaki, M.A.K., Rossouw, J.E., Prentice, R.L., Anderson, G., Howard, B.V., Thomson, C.A., LaCroix, A.Z. and Wactawski-Wende, J., 2013. The Women's Health Initiative hormone therapy trials: update and overview of health outcomes during the intervention and post- 
stopping phases. JAMA: the journal of the American Medical Association, 310(13), p. 1353 .

17. Manson JE, Aragaki AK, Rossouw JE, Anderson GL, Prentice RL, LaCroix AZ, Chlebowski RT, Howard BV, Thomson CA, Margolis KL, Lewis $\mathrm{CE}$. Menopausal hormone therapy and long-term all-cause and cause-specific mortality: the Women's Health Initiative randomized trials. Jama. 2017 Sep 12;318(10):927-38.

18. Manson JE, Chlebowski RT, Stefanick ML, Aragaki AK, Rossouw JE, Prentice RL, Anderson G, Howard BV, Thomson CA, LaCroix AZ, Wactawski-Wende J. Menopausal hormone therapy and health outcomes during the intervention and extended poststopping phases of the Women's Health Initiative randomized trials. Jama. 2013 Oct 2;310(13):1353-68.

19. Mueller KA, Sanchez GJ, Sievert LL. Sources of information and HRT prescribing practices among gynecologists in Puebla, Mexico. Maturitas. 2003 Jun 30;45(2):137-44.
20. Birkhäuser $M H$, Reinecke I. Current trends in hormone replacement therapy: perceptions and usage. Climacteric. 2008 Jan 1;11(3):192-200.

21. Nkwo PO. Suboptimal management of severe menopausal symptoms by Nigerian Gynaecologists: a call for mandatory continuing medical education for physicians. BMC women's health. 2009 Dec;9(1):30.

22. Day A. Lessons from the Women's Health Initiative: primary prevention and gender health. Cmaj. 2002 Aug 20;167(4):361-2.

23. Stefanick ML, Cochrane BB, Hsia J, Barad DH, Liu JH, Johnson SR. The Women's Health Initiative postmenopausal hormone trials: overview and baseline characteristics of participants. Annals of epidemiology. 2003 Oct;13(9 Suppl):S78.

24. Kaplan B, Aschkenazi-Steinberg S, Yogev Y, Nahum R, Sulkes J, Phisher M. Gynecologists' trends and attitudes toward prescribing hormone replacement therapy during menopause. Menopause. 2002 Sep 1;9(5):354-9. 
Table 1. Opinions on efficacy of menopause-HRT

\begin{tabular}{llll}
\hline Menopause Symptoms & N (\%) Effective & N (\%) Ineffective & N (\%) Don't Know \\
\hline Hot flushes & $71(88.8)$ & $4(5)$ & $5(6.3)$ \\
Vulvo-Vaginal Symptom & $60(75)$ & $7(8.8)$ & $13(16.3)$ \\
Low Sex Drive & $51(63.8)$ & $10(12.5)$ & $19(23.8)$ \\
Skin Wrinkles & $35(43.8)$ & $17(21.3)$ & $28(35)$ \\
Dementia & $20(25)$ & $30(37.5)$ & $30(37.5)$ \\
Osteoporosis & $67(83.8)$ & $6(7.5)$ & $7(8.8)$ \\
Coronary Heart Disease & $19(23.8)$ & $40(50)$ & $21(26.3)$ \\
Stroke Prevention & $17(21.3)$ & $40(50)$ & $23(28.8)$ \\
\hline
\end{tabular}

Table 2. Attitudes to recommendation of menopause-HRT

\begin{tabular}{llll}
\hline Menopausal Symptoms & YES & NO & DON'T KNOW \\
& N (\%) & N (\%) & N (\%) \\
\hline Hot flushes & $66(82.5)$ & $8(10)$ & $6(7.5)$ \\
Libido & $60(75)$ & $13(16.3)$ & $7(8.8)$ \\
Vulvo-Vaginal Symptoms & $57(71.3)$ & $13(16.3)$ & $10(12.5)$ \\
Skin Wrinkles & $32(40)$ & $34(42.5)$ & $14(17.5)$ \\
Mood Changes & $53(66.3)$ & $16(20)$ & $11(13.8)$ \\
Sleep Disorder & $33(41.3)$ & $10(12.5)$ & $11(13.8)$ \\
Osteoporosis & $66(82.5)$ & $10(12.5)$ & $4(5)$ \\
Cardiovascular Disease & $30(37.5)$ & $41(51.3)$ & $9(11.3)$ \\
\hline
\end{tabular}

Table 3. Opinions about conditions in which use of menopause-HRT is contraindicated

\begin{tabular}{llll}
\hline CONDITIONS & YES & NO & DON'T KNOW \\
& N (\%) & N (\%) & N (\%) \\
\hline Hypertension & $36(45)$ & $32(40)$ & $12(15)$ \\
Diabetes Mellitus & $26(32.5)$ & $41(51.3)$ & $13(16.3)$ \\
Obesity & $32(40)$ & $35(43.8)$ & $13(16.3)$ \\
Stroke & $52(65)$ & $14(17.5)$ & $14(17.5)$ \\
Breast Cancer & $65(81.3)$ & $5(6.3)$ & $10(12.5)$ \\
Fam Breast Cancer & $45(56.3)$ & $25(31.3)$ & $10(12.5)$ \\
CLD & $49(61.3)$ & $19(23.8)$ & $12(15)$ \\
Fibroid & $23(28.8)$ & $42(52.5)$ & $15(18.8)$ \\
DVT & $58(72.5)$ & $11(13.8)$ & $11(13.8)$ \\
Vaginal Bleeding & $31(38.8)$ & $31(38.8)$ & $18(22.5)$ \\
Endometrial Carcinoma & $58(72.5)$ & $11(13.8)$ & $11(13.8)$ \\
\hline
\end{tabular}


Table 4. Meanopause-HRT knowledge scores compared for different variables

\begin{tabular}{|c|c|c|c|c|c|c|}
\hline Variable & $\mathbf{N}$ & Score & S.D & ANOVA & Association & p Value \\
\hline \multicolumn{7}{|l|}{ GENDER } \\
\hline Male & 56 & 53.4 & 19.9 & & & \\
\hline Female & 24 & 46.0 & 17.2 & 2.48 & 0.12 & $0.03 * * *$ \\
\hline \multicolumn{7}{|l|}{ ETHNICITY } \\
\hline Yoruba & 67 & 49.2 & 19.9 & & & \\
\hline Igbo & 3 & 65.0 & 5.0 & & & \\
\hline Hausa & 1 & 50.0 & - & & & \\
\hline Nupe & 1 & 70.0 & - & & & \\
\hline Others & 8 & 60.6 & 14.7 & 1.30 & 0.07 & 0.28 \\
\hline \multicolumn{7}{|l|}{ RELIGION } \\
\hline Christianity & 46 & 53.3 & 18.7 & & & \\
\hline Islam & 33 & 48.2 & 20.3 & 0.68 & 0.02 & 0.51 \\
\hline Atheist & 1 & 55 & - & & & \\
\hline \multicolumn{7}{|l|}{ SPECIALITY } \\
\hline $\mathrm{O} \& \mathrm{G}$ & 19 & 61.6 & 13.0 & & & \\
\hline Physicians & 24 & 52.5 & 19.1 & & & \\
\hline Family Med & 13 & 44.6 & 19.6 & & & \\
\hline Public Health & 15 & 35.6 & 17.8 & & & \\
\hline Interns & 9 & 61.1 & 15.2 & 6.0 & 0.24 & $0.00 * * *$ \\
\hline \multicolumn{7}{|c|}{ HRT AWARENESS } \\
\hline Good & 14 & 58.1 & 24.6 & & & \\
\hline Moderate & 51 & 53.3 & 16.7 & & & \\
\hline Poor & 15 & 38.2 & 18.6 & 3.14 & 0.11 & $0.03 * * *$ \\
\hline \multicolumn{7}{|c|}{ SOURCE OF INFO } \\
\hline Journals & 17 & 55.6 & 17.3 & & & \\
\hline Textbooks & 32 & 55.0 & 17.6 & & & \\
\hline Lectures & 7 & 50.7 & 29.6 & & & \\
\hline Internet & 3 & 50.0 & 18.0 & & & \\
\hline Multiple & 1 & 60.0 & & & & \\
\hline Nil & 20 & 39.7 & 17.5 & 1.76 & 0.13 & 0.12 \\
\hline \multicolumn{7}{|l|}{ FORMAL } \\
\hline Yes & 13 & 68.1 & 13.9 & & & \\
\hline No & 67 & 47.9 & 18.7 & 6.80 & 0.15 & $0.02 * * *$ \\
\hline
\end{tabular}

